
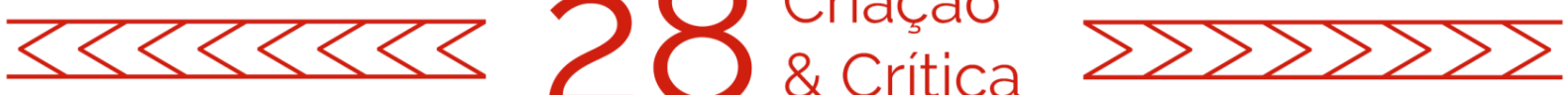

\title{
A CIDADE NO CONTO "O BRASÃO DA CIDADE" E O GESTO PERFORMÁTICO NARRATIVO DE FRANZ KAFKA ${ }^{1}$
}

Camila Wielmowicki Uchoa²

Resumo: A partir do conto "O brasão da cidade" de Franz Kafka propõe-se examinar a construção da imagem da cidade, assim como as relações nela estabelecidas dentre os habitantes. Ainda, literatura e arte relacional serão aproximadas, propondo identificar o conto como obra de arte e sua narração como gesto de exibição dessa obra, questionando a possibilidade de associação da ação performática que o texto desenvolve para o leitor com a noção de performance como prática artística inscrita na arte contemporânea.

PALAVRAS-CHAVE: cidade, Kafka, performance, literatura, arte relacional.

\section{THE CITY IN THE TALE “THE CITY COAT OF ARMS” AND THE NARRATIVE PERFORMATIC GESTURE BY FRANZ KAFKA}

ABSTRACT: Based on Franz Kafka's short story "The city coat of arms" it's proposed to examine the construction of the city's image, as well as the relations established among the inhabitants. Still, literature and relational art will be approached, proposing to identify the short story as a work of art and it's narration as a gesture/action of exhibition of this work, questioning the possibility of associating the performance action that the text develops for the reader with the notion of performance as an artistic practice inscribed in contemporary art.

KEYWORDS: city, Kafka, performance, literature, relational art.

Pensar a conformação das cidades contemporâneas, assim como a rede de relações imbricadas em sua estrutura, exige um retorno à Modernidade, momento em que houve o grande desenvolvimento das metrópoles ${ }^{3}$, a partir dos inventos tecnológicos e mudanças de percepção do espaço, assim como a reestrutura das relações do indivíduo consigo mesmo e com os demais, neste contexto.

A literatura e as artes no geral, sobretudo a partir do século XIX, foram produzindo imagens dessa urbe, não só para representá-la, mas também para tentar compreendê-la. O pesquisador Edson Luiz Souza observa que a verticalidade da cidade se constituiu na imagem de seu progresso, entendendo que o "elogio da aglomeração" nas ruas

\footnotetext{
1 O presente trabalho foi realizado com apoio do Conselho Nacional de Desenvolvimento Científico e Tecnológico - CNPq.

2 Doutoranda do Programa de Pós-Graduação em Letras - Literatura, Cultura e Contemporaneidade, da Pontifícia Universidade Católica do Rio de Janeiro (PUC-Rio). E-mail para contato: camiuchoa@gmail.com.

${ }_{3}$ As condições que permitiram esse desenvolvimento das metrópoles europeias foram possibilitadas, certamente, pelas relações de dominação e exploração que estas estabeleceram com os territórios, através do colonialismo. O momento da modernidade identificado aqui é a segunda fase da modernidade apresentada por Marshall Berman em Tudo que é sólido desmancha no ar (1988, p.13), entre os séculos XVIII e XIX, caracterizada por uma agitação de ideários iluministas e revoluções, com um intenso desejo de mudanças, e ao mesmo tempo dicotômico, com a transformação do mundo pelas novas tecnologias.
} 

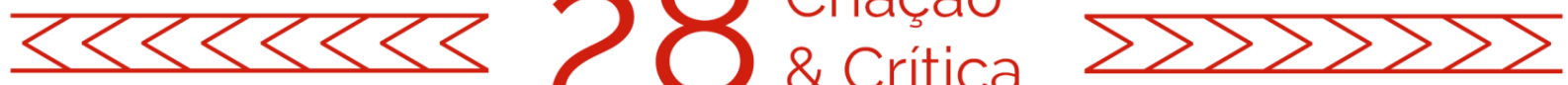

representou o desejo desesperado por uma ascensão econômica-social. O autor aponta: "chegar no topo funciona como o motor da ação. Trata-se, como sabemos, de uma captura por uma imagem ideal." (SOUZA, 2005, p.12). Segundo o autor, essa imagem ideal das cidades teria nascido de um projeto utópico de "materialização tangível das relações humanas", que remontaria às origens da "revolução urbana"4 há cinco mil anos atrás no oriente. Contudo, hoje a visão utópica teria sido substituída justamente pela materialização do progresso através dos objetos de consumo, na tentativa de compensar um vazio de projetos maiores por ideários humanos ${ }^{5}$.

Renato Cordeiro Gomes, em seu livro Todas as cidades: a cidade (1994) observou que essa representação imagística da cidade está sempre ligada às metáforas visuais. Essas podem estar ligadas à natureza, serem de caráter orgânico - identificadas com/como o corpo humano, por exemplo - e sempre buscam a leitura mais apreensível, portanto, mais familiar, dessa urbanidade.

Ao lado dessa vertente imagética, que por sua recorrência forma uma tradição, como indica o autor, há também a vertente diagramática, em que "o diagrama é constantemente redesenhado para englobar as mudanças, uma vez que o espaço não é isolável de uma temporalidade determinada." (GOMES, 1994, p. 83) O diagrama representa assim, a mobilidade e volatilidade características do lugar, através de esquemas, gráficos, traçados que descrevem, resumem e explicitam, sobretudo, as estruturas arquitetônicas para representar os contornos da cidade. $O$ pensador destacou que esse processo de metaforização é uma estratégia para sustentar a leitura de um texto urbano que é inconstante; identifica assim, sintomas da ilegibilidade ${ }^{6}$ das megalópoles contemporâneas:

a incerteza sobre a significação de muitos fragmentos simultâneos; a perda por parte de seus habitantes da habilidade em interpretar a si próprios e o entorno; a coexistência de linguagens e das variadas mídias. E ainda: a comunicação de grupos heterogêneos através do espaço; o

\footnotetext{
${ }^{4}$ Revolução urbana foi um termo cunhado pelo arqueólogo Vere Gordon Childe, na década de 1930, usado não só na arqueologia, mas também na história e antropologia, para entender o surgimento das primeiras cidades, sobretudo no oriente médio. Em sua pesquisa, Childe indica dois períodos de grande transformação social, revoluções que afetariam todos os departamentos da vida humana. O primeiro seria a revolução neolítica, que representaria a mudança do modo da caça e coleta para o da agricultura (que implicaria em um modo de vida mais sedentário, saindo do nomadismo e estabelecendo lugares, "fazendas" para o sustento das famílias) e em seguida a revolução urbana, mais ligada às transformações das instituições sociais e suas práticas, com o poder nas mãos dos reis, a instituição de governos e estratificação social, diversas atividades econômicas se expandindo e construção das primeiras cidades. Ler mais em: https://www.jstor.org/stable/27715085?seq=1 (artigoV. Gordon Childe and the Urban Revolution: a historical perspective on a revolution in urban studies de Michael E. Smith)

${ }^{5}$ Visto que, em um tempo "pós" (RANCIÈRE, 2014, p.204), a partir dos anos 1960, houve o fim do regime histórico como ideia de progresso, com grande pessimismo; as grandes narrativas e os planos foram abandonados em virtude de terem contribuído para a formação de regimes totalitários causadores das grandes guerras mundiais e demais conflitos no século XX.

${ }^{6} \mathrm{O}$ autor Renato Cordeiro Gomes usa este termo para se referir à incapacidade de compreender os variados movimentos da cidade, descritos a seguir no trecho destacado.
} 

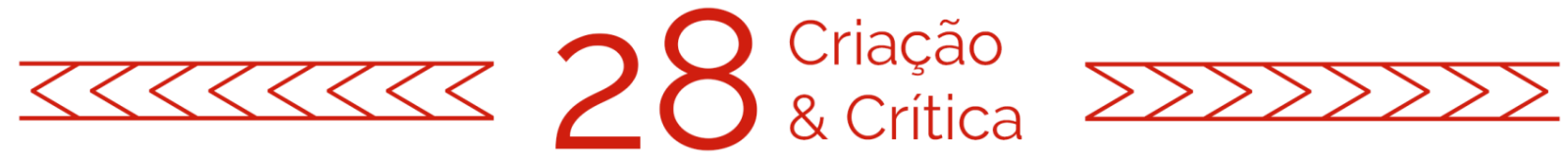

desenvolvimento de uma cultura da individualidade e das formas de violência. (GOMES, 1994, p. 85)

Para representar esse cenário de incertezas e fragmentação observado na contemporaneidade, ele vai opor a imagem da cidade "celeste", utópica ${ }^{7}$, que não se realiza nunca, à imagem da Torre de Babel que "prolifera, cada vez mais sofisticada e ilegível, performática, fazendo e desfazendo suas torres, não mais de tijolos cozidos, mas de concreto, aço e vidro, trazendo ainda inscrito em seu emblema o signo da não permanência, da destruição" (GOMES, 1994, p.90).

Neste sentido, segundo o autor, o mito de Babel seria um suporte semântico para entender essa ilegibilidade da cidade moderna, já que propõe uma "nova realidade narrativa" através da moldura bíblica. Tal operação é utilizada por Franz Kafka, em seu conto O brasão da cidade (Das Stadtwappen). Este conto se encontra reunido na obra póstuma intitulada Narrativas do espólio (2002) (ErzählungenausdemNachlass), organizada por seu amigo Max Brod e lançada em 1931, tendo sido traduzida por Modesto Carone em 2002.

A narrativa ${ }^{8}$ evoca o mito de origem bíblica, citado no livro do Gênesis, como a tentativa do povo advindo de Caim de construir a Torre de Babel, uma edificação que tocasse o céu, com pretensão de igualar o poder humano ao divino ou ascender a essa divindade. Segundo consta nos escritos da Bíblia, Deus teria visto essa tentativa como um ato de soberba e arrogância por parte do povo e decidiu destruir a torre, criando diferentes idiomas e embaralhando assim a comunicação - que anteriormente era feita em uma única língua - promovendo o caos entre os homens. ${ }^{9}$

Kafka coloca como questão primeva da história a construção dessa torre. Contudo, entende-se que não há uma preocupação em terminá-la por parte das pessoas que a constroem, uma vez que a ideia de progresso indica segurança na aquisição de novos conhecimentos. Desta forma, os homens vão deixando para as gerações seguintes concluírem essa edificação - certos da ideia de que os sucessores vão sempre achar ruim o trabalho de seus predecessores e vão destruí-lo para começar tudo de novo - e se voltam para a criação da cidade dos trabalhadores, que vai sendo erigida em meio a disputas de líderes, intervalos com embelezamentos dos lugares - que despertam a inveja e a cobiça dos demais - e, por conseguinte, guerras entre as nações. No caminhar da segunda ou da terceira geração a construção da torre já é vista como algo sem sentido. Embora haja a afirmação de que "enquanto existirem homens, existirá também o forte desejo de construir a torre até o fim", as pessoas já estariam muito ligadas entre si apesar da belicosidade - e não conseguiriam abandonar a cidade. Assim, a retomada

\footnotetext{
${ }^{7}$ Celeste no sentido bíblico, do paraíso celestial de um Deus, e celeste como o lugar ideal, impossível de se realizar, como desenvolve Thomas Morus em a Utopia (1516).

${ }^{8} \mathrm{O}$ conto na íntegra está disponível em anexo.

${ }^{9}$ Outra referência apontada como explicação da Torre de Babel segue a linha histórica na qual, a torre fora inspirada em um templo Zigurate na mesopotâmia, atribuído a Nabucodonosor. O templo que era uma morada dos deuses indicaria com sua forma verticalizada o contato dos homens com o cósmico, divino e também o poder político do seu governante com seu tamanho imponente.
} 

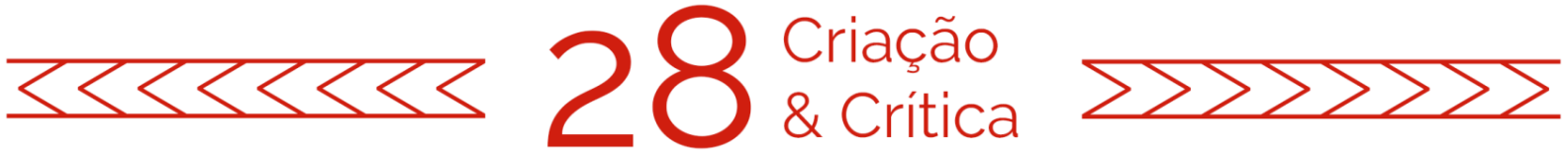

dessa empreitada só se justificaria após o armistício geral. O desfecho do conto se dá com a afirmação do clima de nostalgia pelo dia profetizado da destruição da cidade por um punho gigantesco, em cinco golpes de rápida sucessão, o mesmo punho que consta estampado no brasão desta cidade.

Além de ilustrar a "ilegibilidade" da urbe (GOMES, 1994, p.85), a escolha deste conto de Kafka também destaca nos pilares centrais de formação da cidade moderna assim como da contemporânea - o que há de mais importante nela, que é seu caráter relacional e performático, tanto no sentido de performar, traçando e escolhendo caminhos, como também no sentido da performance como atuação e interação no mesmo ambiente de seus habitantes. Além disso, sua linguagem realiza um movimento muito singular em direção ao leitor, que muitas vezes vai contra essa relação estabelecida no território urbano, contido na narrativa, como será demonstrado em seguida.

É possível observar que o sustentáculo de formação citadina acontece em função da integração de três elementos, processo que se inicia com a presença humana: i) a mão de obra braçal, criadora das estruturas concretas da metrópole; ii) a arquitetura distribuída que organiza o espaço, que ocorre em função do trabalho original; iii) as pontes feitas pela performance humana dentro desses espaços delimitados. Embora aqui a performance seja entendida como o desempenho do indivíduo, baseado no sentido que o diretor de teatro Richard Schechner faz no artigo Performer (2009, p. 336) das quatro etapas do processo do performer, no sentido de atuação do ator, podemos verificar que essas mesmas etapas são descritivas das relações observadas na cidade, como ritmos pulsantes e que podem, ou não, acontecer simultaneamente.

As etapas mencionadas por Schechner são (2009, p.36): entrar em contato consigo mesmo - o que pode estar associado ao ambiente privado, como por exemplo, o momento do indivíduo solitário em casa; entrar em contato consigo por meio do outro - que pode ir ao encontro da ideia dos passantes nas ruas, que se esbarram, ou não; relacionar-se com os outros sem uma história ou estrutura formal elaborada - o que pode ser pensado como as relações momentâneas sem profundidade do cotidiano, como por exemplo, relações de trabalho ou de serviço e consumo, onde o contato é superficial; por fim, relacionar-se com os outros dentro de uma história ou estrutura formal elaborada - o que pode explicitar as escolhas individuais de partilha e identificações diretas dos indivíduos. ${ }^{10}$

Para além dessa potência integradora da performance urbana, que pode desenvolver uma consciência de grupo, a cidade de Kafka não é apresentada como acolhedora ou que integra seus habitantes, mas sim em seu caráter progressista que ironicamente faz com que o trabalho das gerações primeiras seja sempre destruído pelas gerações mais novas, em um cenário mais opressor, em que os viventes estão sempre em disputas e guerras, por questões superficiais como o embelezamento dos espaços.

\footnotetext{
${ }^{10}$ É possível também pensar essas fases como um processo "evolutivo" do ser humano, que primeiramente precisa aprender a dominar seus instintos íntimos e fazer um reconhecimento de si para em seguida conseguir estabelecer relacionamentos interpessoais e compartilhamentos em um mesmo ambiente, algo que atravessa as discussões de Freud, como em seu texto Considerações atuais sobre a guerra e a morte (1915).
} 

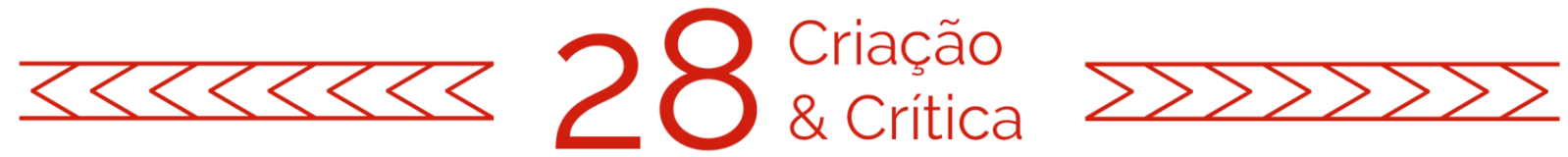

É claro que esta escolha se relaciona com diversos fatores, sobretudo com a questão política, sendo uma crítica à ideia do progresso, que estimula conflitos - cada grupo quer ser melhor que os demais -, e a mecanização e automatização da vida, como o ritmo de vida alienado do trabalhador das fábricas, a desvalorização da sua mão de obra e a desvalorização do tempo do lazer, como também o fato da geração seguinte sempre destruir o trabalho da anterior, que coloca no centro a questão moderna, de uma tradição de rupturas, como destaca Octavio Paz no livro Os filhos do barro (PAZ, 1984, p.17) que não permite que se estabeleça nenhum projeto de cidade-vida duradouro.

Para dialogar com esse cenário o autor utiliza a metáfora fantástica da Torre de Babel11 para falar de algo que não é compreensível na vida real, a própria construção da cidade moderna. A cidade não se resolve nunca porque está sempre em uma composição eterna, incorporando novas tecnologias, maquinários, e como no mito de babel, após sua destruição, os homens não se entendem. É como se no conto a torre tivesse sido construída, destruída, e cada um tivesse um idioma e, por conseguinte, o caos geral. Porém, a torre não fora nem concluída parcialmente. Assim também é como se a cidade fosse uma espécie de construção dessa Torre de Babel ao contrário, que se no sentido original é erigida com o intuito da união, desta vez, a cidade do conto é feita já na ordem da desunião parcial, com áreas específicas, delimitadas para cada grupo.

Essa inversão da história bíblica com a criação da cidade se identifica com o que Günther Anders entende em Kafka: Pró e contra - os autos do processo (2007) como a "deformação como método"12, em que Kafka remete o objeto a uma situação artificial experimental com o intuito de tocar o cerne da realidade. Desta forma, ao colocar a cidade na preferência de construção em detrimento da torre que iria até o céu, e, portanto, representaria o imaginativo - o que igualaria a todos ao nível divino - faz com que o leitor volte sua atenção para essa mesma cidade dos trabalhadores, terrena, que nivela todos os habitantes em uma rotina mecânica e por muitas vezes massacrante na vida real.

Assim, se anteriormente a Babel fora identificada como a realidade em contraposição à cidade celeste, agora ela está sendo vista como o projeto utópico - e que, portanto, não se realiza nunca - se opondo à cidade apresentada que revela a sua verdade da desordem.

Da mesma maneira, essa "deformação" está presente também no absurdo de pensar sobre a inviabilidade de um processo de paz geral entre os habitantes (que acontece também no mundo real), com a afirmação da impossibilidade da torre à espera do armistício geral que, fica entendido implicitamente, nunca chegará a acontecer.

\footnotetext{
${ }^{11}$ Uma escolha que pode estar atrelada à sua origem judaica, apesar de ele não ter sido um judeu que demonstrasse sentimento de pertencimento para com a comunidade judaica ou a religião. Também pode-se pensar que talvez a Babel seja alguma representação da cidade de Praga pelos olhos do autor.

${ }_{12}$ Anders diz que o método não fora reconhecido, que outros intérpretes da obra de Kafka viam esse traço de deformação apenas como "exótico", "onírico" ou "simbólico". (2007, p.16)
} 

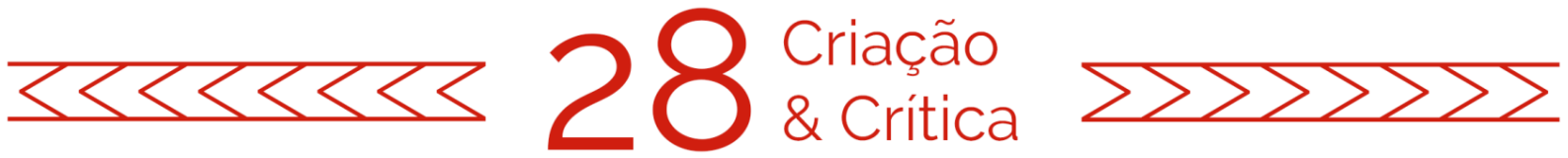

Outro elemento que pode ser destacado é o brasão da cidade. O brasão que é visto como um símbolo de representação de um grupo, ou coletividade ${ }^{13}$, estampa um punho, o mesmo citado na profecia de destruição desta mesma cidade. Aqui se identifica o traço que Anders chama de "trivialidade do grotesco", que provoca uma "dessensibilização do tom", misturando horror e conforto e que traz também uma função didática14. "O não anúncio do incomum confere ao incomum, até mesmo ao pavoroso, um bem-estar pequeno-burguês muito característico"15 (ANDERS, 2007, p.21). É possível assim, fazer uma relação do conto com o exemplo que o autor dá, do personagem Gregor Samsa de $A$ Metamorfose (1997), que não vê surpresa em acordar transformado em uma barata, com o fato do brasão da cidade estampar o punho que, segundo consta na profecia, irá destruí-la. Este punho, que pode representar um movimento de entropia revelando tanto a força de trabalho dos homens que a constroem, como também tem o poder de acabar com ela, com suas guerras, não parece chamar a atenção desses habitantes.

É preciso lembrar que a obra de Kafka foi publicada postumamente por seu amigo e testamenteiro Max Brod, contra a vontade do autor. O fato de ele querer que seus escritos fossem completamente destruídos após sua morte pode estar associado à condição de não se sentir pertencente a nenhum grupo ou lugar durante toda sua vida.

Esse é um traço observado na voz enunciativa do texto em questão. É uma voz estranha que está sempre exterior aos acontecimentos, sem uma identidade e um tempo definidos. Não há como saber o que essa voz domina, já que o narrador não afirma a certeza dos fatos; por isso também não é possível dizer que é um narrador onisciente. Como afirma Modesto Carone ${ }^{16}$ :

Essa visão, ou falta de visão das coisas, não é só tema da obra, mas também está introjetada nela através de um narrador literariamente qualificado, mas antionisciente (ou insciente) que se torna, assim, a formalização estética do que ocorre no plano da matéria narrada. (CARONE, 2009, p.107)

E aqui, a ação de querer construir a Torre de Babel, mas não fazê-la está de acordo com a "alopraxia" que observou mais uma vez Anders (2007, p.25) - esta que representa o ato de querer realizar algo, mas acabar, por fim, realizando outro, que no caso, era voltar-se à edificação da cidade dos trabalhadores que construiriam a torre; demonstra que não só o narrador não tem domínio sobre a história, como também os personagens citados - os indivíduos da cidade, que são apresentados como uma massa

\footnotetext{
$13 \mathrm{Na}$ Europa do século XII há o estudo da heráldica. Primeiramente símbolo de homenagem, posteriormente status de nobreza. No século XIX com o declínio da aristocracia perde a importância e no século XX retorna como símbolo coletivo como, por exemplo, em bandeiras de municípios e estados.

${ }^{14} \mathrm{O}$ autor dá um exemplo: para perceber a feiura da cidade seria mais efetivo um álbum com fotos de imagens chocantes de casas feias do que uma volta pelas ruas da cidade que o indivíduo costuma frequentar em seu cotidiano.

${ }^{15}$ Refere-se aqui ao bem estar do burguês, como algo suave, sossegado, que está protegido no ambiente privado, longe dos grandes perigos da rua, na modernidade.

${ }^{16}$ Principal tradutor da obra de Kafka no Brasil.
} 

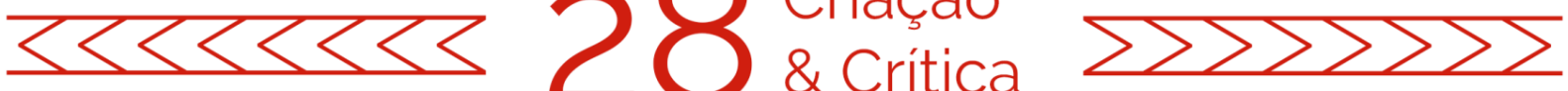

anônima, são reconhecidos como sua função de trabalho - parecem não ter uma segurança sobre o caminho a seguir.

Assim, esta escolha de enunciação, como também a "alopraxia" supracitada, segundo o estudioso, poderiam estar ligadas a impressão que temos do desconforto social de Kafka que, parece, se achava um estranho em vida, um outsider. Sendo um judeu indiferente, não se sentia representado nem pelo grupo de burgueses do qual descendia, nem pelo grupo de judeus do leste; era tcheco, mas falava e escrevia, em alemão, era um judeu alemão, mas não era um boêmio. Se houve certa incerteza quanto à identificação dele com um grupo étnico, religioso e/ou local, sua vida profissional também apresentava o mesmo quadro. Como destaca Anders (2007), Franz Kafka trabalhava em um escritório de seguros, e apesar de não se identificar por completo com a burguesia, como filho de burgueses também não se adaptava ao trabalho operário; seu trabalho era burocrático, mas sentia-se um escritor. A esse cenário de espelho partido que refletia sua identificação fragmentada para com todas as coletividades nas quais foi "estrangeiro" em vida, soma-se também o fato que escreve suas observações do mundo no início do século $X X$, em um período entre guerras mundiais, além de ter uma condição de saúde fragilizada devido à tuberculose, que podem também ter influenciado na escolha de seus temas sobre angústia, perda, culpa, como também a "linguagem de guerra" presente no brasão da cidade. ${ }^{17}$

Deste modo, sua escrita estaria atrelada a essa condição de não pertencimento, vendo assim o mundo de fora (ANDERS, 2007), sua eterna promessa de chegada dos personagens, nos lugares e atos, que nunca se concretizam, pode representar a vontade que o autor tem de buscar, e falhar com essa identificação coletiva. A atitude existencial expressa, também reforça a enunciação avessa ao vínculo do narrador e dos personagens em geral. Esta, por sua vez, está atrelada a formas de alienação - família, religião, profissão - que não podem fazer nada ante o fato do simples existir, e que geram certa inércia aos personagens diante dos acontecimentos nas histórias.

É importante também notar que o caráter de estranhamento causado pelas imagens deslocadas/deformadas, por um método que confronta os extremos da imaginação e da realidade, e pela dessensibilização do grotesco, juntamente à linguagem que Kafka usa, essa voz distante, de enunciação impessoal, sobretudo com um narrador de uma voz passiva sintética, não tem um movimento, performance, que envolve o leitor e o direciona para dentro da história.

O conto pode ser visto como uma obra de arte e a narração como um gesto de exibição dessa obra. Seria possível então associar essa ação performática do texto com a performance como prática artística?

Para fazer tal aproximação, no entanto, é necessário antes entender o contexto em que surge essa prática artística da performance. Nas décadas de 1980 e 1990 as práticas artísticas em geral começaram a ser questionadas em seus moldes formais, que não

${ }^{17}$ Com os termos "líderes", "nacionalidades", "armistício", "batalha" e "belicosidade". 

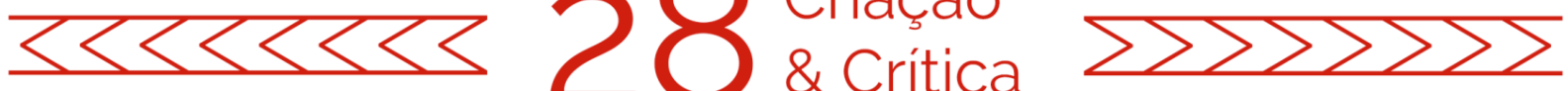

atendiam mais aos questionamentos de um mundo que parecia desgastado em seus conceitos de História, Arte, Família, o que possibilitou a formação do pensamento moderno.

O crítico de arte e curador Nicolas Bourriaud notou que as formas artísticas começaram a assumir conformações extremas ou "clandestinas" como resposta ao controle de governos que buscavam a canalização das relações humanas em estruturas controláveis, simplórias e com repetibilidades, em conformidade com um mundo ordenado pela divisão, especialização e mecanização humana, centrado no lucro. Ao mesmo tempo notou que o processo agudo de urbanização pós segunda-guerra mundial trouxe intensa mobilidade, inchaço das cidades, diminuição dos espaços habitáveis e consequentemente a redução na escala de móveis e objetos - e assim, o fácil manejo destes - o que também possibilitou a "experiência de proximidade" das pessoas dentro desse espaço metropolitano (BOURRIAUD apud ALTHUSSER, 2009, p.21).

Segundo o autor, as obras foram além da forma material, plástica, e tornaram-se elementos de ligação entre os indivíduos, respondendo ao fracasso da Modernidade que transformou as relações interpessoais em produtos. O intuito seria o de aprender a habitar o mundo sem a ideia evolutiva histórica vigente até então, sem utopias, usando a própria realidade presente como perspectiva de transformação da vida. Bourriaud postula esse novo paradigma, como a estética relacional, onde a obra é "interstício social", processual, comportamental, de interação entre os indivíduos no espaço e tempo presentes, "um encontro fortuito duradouro" (2009, p.27). Sua política se encontra justamente nesses vínculos temporários, que problematizam a automatização e mecanização da vida nos espaços cotidianos, principalmente, da cidade ${ }^{18}$. É preciso frisar, no entanto, que uma obra em um suporte de vídeo ou uma colagem podem representar essa intenção de troca sem que os indivíduos participem necessariamente de uma performance.

A performance enquanto gênero artístico é um tipo de arte relacional. Gestada um pouco antes, na década de 1970, como crítica e resistência à mercantilização, não utiliza obrigatoriamente materiais, o corpo é o meio direto de expressão, as apresentações são efêmeras, e são realizadas em locais que nem sempre fazem parte do circuito da arte (galerias, museus, centro culturais...), como as ruas. O pesquisador Fernando Gonçalves destaca que o corpo é o instrumento que vai ser posto em uma relação de estranhamento com outros objetos, lugares, situações e outros corpos, suspendendo os sentidos e condicionamentos usuais destes, ainda que brevemente, para lhes dar novas significações e mudar percepções pré-estabelecidas. Ele aponta que a origem da performance não estava atrelada a uma negação às práticas anteriores,como na tradição moderna, mas por expansão, por mescla e excessos:

Como linguagem, vai resultar de uma verdadeira catálise que incorpora elementos das artes plásticas (o imagético e a collage), do teatro (a cenografia, a iluminação, os jogos de apresentação, dentro da tríade

\footnotetext{
${ }^{18}$ Bourriaud usa a imagem da arte relacional como um modelo social que promove essas relações humanas em comparação com a arquitetura, que é promotora de itinerários para os seus ocupantes.
} 

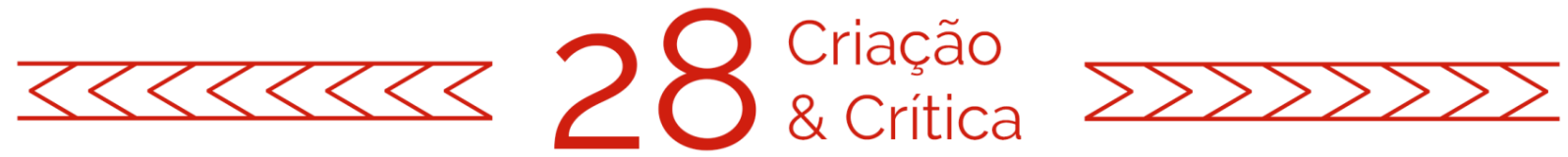

guinsburgiana ${ }^{19}$ ), da dança (o movimento, os ritmos e os tempos do corpo), da música (a capacidade de atingir os sentidos por uma materialidade sonora). (GONÇALVES, 2003, p.17)

Desta forma, para o autor, a performance funciona como um composto "artecorpo-comunicação", deslocando a noção de transmissão de uma mensagem e centrando-se no processo. Um processo muito mais centrado no "chegar lá" do que no "chegar lá", de acordo com Robert Schechner ${ }^{20}(2009$, p.337), que reafirma que a ênfase está no fazer e não no que é feito. O autor ainda afirma que a performance funciona porque ao mesmo tempo que segue um script através dos padrões disciplinados, regras à execução da obra, tem um grau de liberdade, e está sujeita ao acaso, por conta do impulso íntimo de cada um que participa dela ${ }^{21}$.

Assim, a literatura de Kafka entra em conflito já com a principal premissa que a arte relacional e a performance sustentam: o vínculo, que se faz na necessidade do encontro do espectador com a obra/ou com o autor, para participar dela, ou até mesmo do público na produção dela, ainda que somente por um instante. Como o movimento do escritor é no sentido de causar um estranhamento não só no enredo, mas trazer a impessoalidade à narrativa, como já descrito anteriormente, não há possibilidade de identificação do leitor com esse narrador, ou mesmo com a história, que são sempre imprecisos e inconclusivos.

Por outro lado, essa mesma imprecisão narrativa está de acordo com o paradigma estético relacional, que trabalha a imaginação dos participantes nas obras. Bourriaud diz que a realidade é o que é possível comentar com os demais. É um produto da negociação, onde o sentido é criado como um acordo entre artista-espectador na interação com a obra. ${ }^{22}$ Se a imaginação se fixa no real para poder fazer o intercâmbio e reduzir a mecanicidade dos indivíduos na performance, o trabalho de interpretação especulativa em Kafka é também um processo, pode ser uma tentativa de tirar o leitor desse gesto mecânico que muitas vezes a leitura imprime quando apresenta a realidade de forma direta. Deste modo, como o artista performático opera sentidos, criando "focos mutantes de subjetivação" (BOURRIAUD, 2009, p.138), o gesto narrativo de Kafka carrega essa ambiguidade de sentidos.

Da mesma maneira, o fato da obra relacional se realizar com objetos parciais, fragmentários, inacabados - e não possuírem uma assinatura, pois essa pressupõe a

\footnotetext{
${ }^{19}$ A tríade Guinsburgiana é composta pelo texto, pelo ator e pelo público.

20 Diretor do Performance Group - grupo de teatro de NY (iniciado na década de 1970) que trabalha na linha do chamado teatro ambiental - termo que o diretor pegou emprestado do artista Allan Kaprow sobre performance, assamblages e happenings - se constituiu testemunho histórico do teatro experimental dos EUA, fonte de inspiração para o teatro performático e político atual. Na performance ambiental todos os elementos são vivos (são reais).

${ }^{21}$ É possível dizer que dentro do teatro, a performance artística estaria mais de acordo com a corrente do teatralismo, já que, o acaso que pode ocorrer, pega o indivíduo desprevenido, levando-o para o extremo da sensorialidade ou emoção. Grotowiski e Artaud são representantes desse teatro, que trabalham com a situação extrema da ação, para revelar a essência do ser humano.

${ }^{22} \mathrm{E}$ quanto a esse aspecto, Bourriaud faz uma crítica afirmando que quando alguém diz que não consegue enxergar sentido em uma obra de arte é porque não fez um bom trabalho de imaginação.
} 

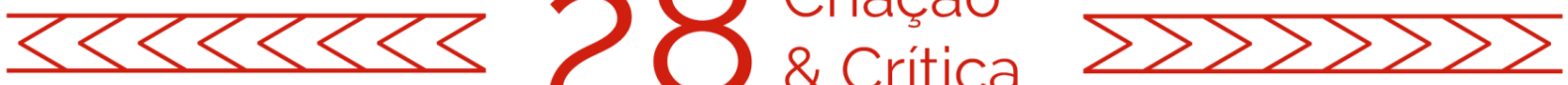

perda de uma polifonia; se coaduna com o comportamento do narrador sem identidade, que também não imprime assinatura, cria possibilidades de interpretações para quem o escuta, lê, não deixando de ser um convite ao leitor para participar dessa escrita, ainda que em momentos distintos. Como pontua a estudiosa Jeanne-Marie Gagnebin a obra de Kafka "nos convida a uma literatura sem língua materna, nem pátria, a um pensamento sem origem assegurada nem objetivo, além das relações bem estabelecidas de propriedade e identidade" (GAGNEBIN, 2015, p.13).

É possível pensar também que a escolha por um narrador que não está em um tempo definido marca um gesto político que foge à narrativa única, assim como a opção por textos mais curtos poderia representar o "encontro fortuito" no espaço-tempo da obra $^{23}$, de que fala o curador francês, visto que esta característica de extensão menor da escrita possibilita sua maior circulação, e, por conseguinte, maior possibilidade para traduções desses textos em diversas línguas, e sua disseminação, potencializando o intercâmbio cultural e as discussões das ideias contidas nessa literatura.

Por fim, nota-se que o gesto performático narrativo kafkiano tem alguns pontos que dialogam com a estética relacional e com a performance, mas não pode ser usado com o mesmo sentido da prática performática da arte contemporânea. Enquanto a literatura fixa a imagem do acontecimento na história narrada e tem uma produção material do seu gesto de enunciação, que é a escrita, a performance promove um processo de choque e restauração, isto é, causa um estranhamento de corpos, objetos e situações, para depois fazê-los retornar ao comum, cotidiano, trabalhando a questão do tempo da obra realizada no instante onde "o tempo perde em cronologia para ganhar em intensidade" (GONÇALVES, 2003, p.27) e não há a necessidade da materialização desta obra. ${ }^{24}$ Embora a performance, na prática contemporânea, possa levar à construção dessa imagem da cidade para o campo da experiência real, como uma tentativa de um vínculo coletivo, entende-se que o que Kafka entrega em seus textos pode ser visto como uma maneira de tentar estabelecer um vínculo com o seu leitor, o autorizando a repensar a construção imagética da cidade através de metáforas. Kafka estaria assim imprimindo a sua marca no mundo e se reconhecendo como integrante do mesmo.

\section{Referências Bibliográficas}

ANDERS, G.Kafka: pró e contra. Os autos do processo. Tradução de Modesto Carone. São Paulo: Cosac Naify, 2007.

\footnotetext{
${ }^{23}$ A opção por textos mais curtos pode estar de acordo também com o que Walter Benjamin deduz sobre a condição de emudecimento, ou narrativas mais concisas dos autores em períodos pós-guerras. Como Kafka é um autor que vive em um período histórico pós-guerra, essa característica pode ter influenciado de certa maneira a sua escrita.

${ }^{24}$ Apesar da possibilidade de fazer o registro dessa performance, por exemplo, através da gravação em vídeo, este não configura a obra em si; para além de um registro, poderia ser visto como uma outra obra, a partir da primeira, o que é muito discutido no meio artístico e até hoje não se chegou a um consenso sobre essa consideração.
} 

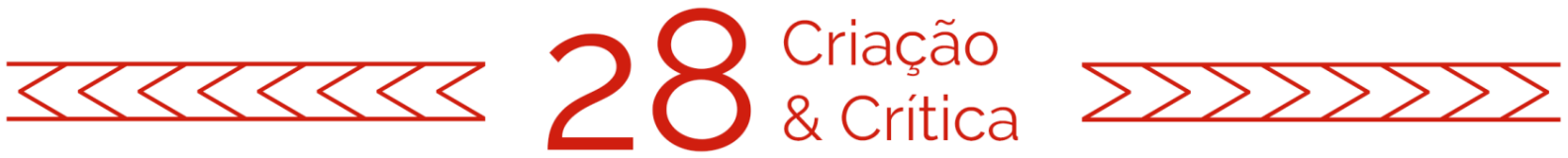

BERMAN, M. Tudo que é sólido desmancha no ar: a aventura da modernidade. Tradução de Carlos Felipe Moisés, Ana Maria L. Ioriatti. São Paulo: Companhia das Letras, 1986.

BOURRIAUD, N. Estética relacional. Tradução de Denise Bottman. São Paulo: Martins Fontes, 2009.

CARONE, M. Lição de Kafka. São Paulo: Companhia das letras, 2009.

"O discurso e a cidade: quatro esperas". Literatura e Sociedade. Revista do Departamento de Teoria Literária e Literatura Comparada, da Faculdade de Filosofia, Letras e Ciências Humanas da Universidade de São Paulo, v. 14, n. 12, p.164-175, 2009. GAGNEBIN, J. "Deslocamentos e deformações em Kafka". Viso- Cadernos de estética aplicada. Revista eletrônica de estética - Programa de pós-graduação em Filosofia da Universidade Federal Fluminense. Rio de Janeiro, v.4,n 17, p.1-14, 2015.

GOMES, R. Todas as cidades, a cidade. Rio de Janeiro: Rocco, 1994.

GONÇALVES, F. Comunicação e experimentações com a linguagem na performance. In: LOGOS-COMUNICAÇÃO E UNIVERSIDADE, ed. Ano 10- n 18- $1^{\circ}$ Semestre/ 2003, Rio de Janeiro, UERJ,p. 10-29.

KAFKA, F."O brasão da cidade”. In: KAFKA, F. Narrativas do espólio. Tradução de Modesto Carone. São Paulo: Companhia das letras, 2002.

A Metamorfose. Tradução de Modesto Carone. São Paulo: Companhia das letras, 1997.

PAZ, O. "A tradição da ruptura". In: PAZ, O. Os filhos do barro; do romantismo à vanguarda. Rio de janeiro: Nova Fronteira, 1984.

RANCIÈRE, J. "Em que tempos vivemos?". Serrote, Rio de Janeiro, n. 16, p.203-223Y, 2014.

SCHECHNER, R. "Performer". Revista do PPG em Artes Cênicas, São Paulo, n.9, p. 333365, 2009.

SMITH, M."V. Gordon Childe and the Urban Revolution: a historical perspective on a revolution in urban studies". The town planning Review. Liverpool, v. 80, n.1, p. 3-29 2009. SOUZA, E. "Cidades de morar, cidades de sonhar". In: VILHENA, J., CASTRO, R., ZAMORA, M. (org.). A cidade e as formas de viver. Rio de Janeiro: Editora Museu da República, 2005.

\section{Anexo}

\section{O Brasão da cidade}

No início tudo estava numa ordem razoável na construção da Torre de Babel; talvez a ordem fosse até excessiva, pensava-se demais em sinalizações, intérpretes, alojamentos de trabalhadores e vias de comunicação, como se à frente houvesse séculos de livres possibilidades de trabalho. A opinião reinante na época chegava ao ponto de que não se podia trabalhar com lentidão suficiente, ela não precisava ser muito enfatizada para que 

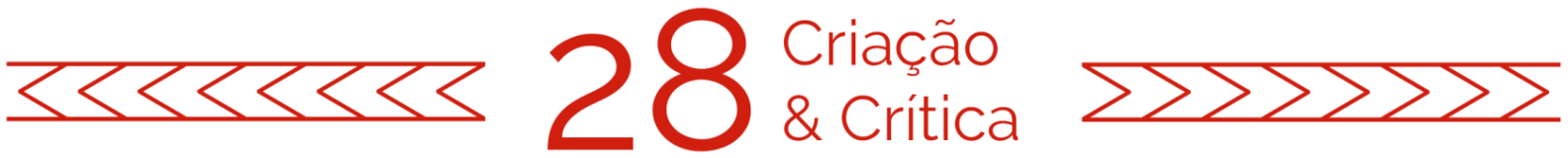

se recuasse assustado ante o pensamento de assentar os alicerces. Argumentava-se da seguinte maneira: o essencial do empreendimento todo é a ideia de construir uma torre que alcance o céu. Ao lado dela tudo o mais é secundário. Uma vez apreendida na sua grandeza essa ideia não pode mais desaparecer; enquanto existirem homens, existirá também o forte desejo de construir a torre até o fim. Mas nesse sentido não é preciso se preocupar com o futuro; pelo contrário, o conhecimento da humanidade aumenta, a arquitetura fez e continuará fazendo mais progressos, um trabalho para o qual necessitamos de um ano será dentro de cem anos realizado, talvez em meio e além disso, melhor, com mais consistência. Por que então esforçar-se ainda hoje até o limite das energias? Isso só teria sentido se fosse possível construir a torre no espaço de uma geração. Mas não se pode de modo algum esperar por isso. Era preferível pensar que a geração seguinte, com o seu saber aperfeiçoado, achará mau o trabalho da geração precedente e arrasará o que foi construído, para começar de novo. Esses pensamentos tolhiam as energias e, mais do que com a construção da torre, as pessoas se preocupavam com a construção da cidade dos trabalhadores. Cada nacionalidade queria ter o alojamento mais bonito, resultaram daí disputas que evoluíram até lutas sangrentas. Essas lutas não cessaram mais, para os líderes elas foram um novo argumento no sentido de que, por falta de concentração necessária, a torre deveria ser construída muito devagar ou de preferência só depois do armistício geral. As pessoas, porém, não ocupavam o tempo apenas com batalhas, nos intervalos embelezava-se a cidade, o que, entretanto, provocava nova inveja e novas lutas. Assim passou o tempo da primeira geração, mas nenhuma das seguintes foi diferente, sem interrupção só se intensificava a destreza e com ela a belicosidade. $A$ isso se acrescentou que já a segunda ou terceira geração reconheceu o sem-sentido da construção da torre do céu, mas já estavam todos muito ligados entre si para abandonarem a cidade. Tudo o que nela surgiu de lendas e canções está repleto de nostalgia pelo dia profetizado em que a cidade será destroçada por um punho gigantesco com cinco golpes em rápida sucessão. Por isso a cidade tem um punho no seu brasão.

Recebido em: 10/08/2020

Aceito em: 19/10/2020

Referência eletrônica: UCHOA, Camila Wielmowicki. A cidade no conto "O brasão da cidade" e o gesto performático narrativo de Franz Kafka. Criação \& Crítica, n. 28, p., dez. 2020. Disponível em: <http://revistas.usp.br/criacaoecritica>. Acesso em: dd mmm. aaaa. 